01; 05.3

\title{
Кластерная модель образования наночастиц и мезообъектов в ударных волнах в тяжелых металлах и при выбросах с их поверхности
}

\author{
(ㄱ Э.Э. Лин
}

Российский федеральный ядерный центр - Всероссийский научно-исследовательский институт экспериментальной физики, Институт фризики взрыва, Саров, Россия

E-mail: postmaster@ifv.vniief.ru

Поступило в Редакцию 17 ноября 2017 г.

На основе кластерной модели рассчитаны наиболее вероятные, средние и максимально возможные размеры наночастиц и мезообъектов, образующихся в процессах ударно-индуцированной перестройки микроструктуры тяжелых металлов и при последующих выбросах частиц с поверхности макроскопических образцов вблизи дефектов кристаллической решетки. Предложенная модель дает полный расчетный диапазон характеристических размеров исследуемых нано- и мезообъектов от $\sim 1 \mathrm{~nm}$ до $\sim 370 \mu \mathrm{m}$.

DOI: 10.21883/PJTF.2018.23.47012.17122

Традиционно теоретическое описание взрывных выбросов частиц с поверхности металлов разделяется на атомистическое и молекулярнодинамическое моделирование, а также на рассмотрение газодинамической стадии процесса формирования пылевых облаков в многофазной среде [1]. В работе [2] предложен твердофазный механизм ударноволнового образования пылевых частиц тяжелых металлов, в частности актиноида [3]. Этот механизм связан с разрушением кристаллической решетки вещества на дефектах структуры в результате разрывов межатомных связей и образования „обломков““ кристаллической решетки атомных кластеров. В дальнейшем происходит коалесценция атомных кластеров (наночастиц) внутри ударной волны (УВ) в результате их фононных возбуждений и взаимной компенсации незадействованных электронных связей поверхностных атомов. 
Предложенный кластерный подход занимает промежуточное положение между атомистическим моделированием и газодинамическими расчетами и основан на представлениях о существовании в кристаллах фононов и точечных дефектов (вакансий и межузельных атомов). Эти „базовые“ дефекты обусловливают разрыв межатомных связей в результате возбуждения колебаний решетки при ударном воздействии и подбарьерных переходов в квантово-механической системе, когда число колебаний во „фронте“ УВ чрезвычайно велико $\left(\sim 10^{2}-10^{3}\right)$. Принципиально возможность квантового туннелирования атомов в кристалле при внешнем воздействии доказана в работе [4]. В [2] на основе дифференциального уравнения для роста среднего размера объектов со временем, полученного в [5] исходя из соотношений неопределенностей координата-импульс в пространстве размеров кластеров $a$ и энергия-время, которые в случае квантовой системы в когерентном состоянии (в приближении гармонических колебаний атомов с одинаковой частотой) выполняются в виде точных равенств, рассчитаны средние размеры наночастиц и мезозерен в УВ, лежащие в диапазоне от $10 \mathrm{~nm}$ до $300 \mu \mathrm{m}$. Данный диапазон охватывает различные режимы твердофазного механизма агрегации объектов: малый поток зародышей на частицу, фронтальные столкновения, касательные взаимодействия, одновременное возбуждение объектов во всем объеме. Можно полагать, что эти режимы соответствуют процессам перестройки микроструктуры металла при ударном воздействии. Перестройка внутри УВ является первичным процессом по отношению к последующему выбросу частиц с поверхности образца при выходе УВ в вакуум, газ или жидкость и при образовании встречной волны разрежения, распространяющейся внутрь твердого образца. Выбросы могут происходить на приповерхностных дефектах кристаллической структуры вещества: вакансиях и межузельных атомах, микрополостях и порах, дислокациях, при движении которых образуются вакансии, а также на межзеренных границах. Можно полагать, что в потоке объектов, образовавшемся в многофазной среде при выбросе наночастиц с поверхности образца, могут происходить коалесценция наночастиц и агрегация мезозерен по описанному выше фононному механизму в режимах малого потока зародышей на частицу и касательных взаимодействий объектов.

В настоящей работе приведены расчеты характеристических размеров наночастиц и мезообъектов, которые могут образоваться в процессе ударно-индуцированной перестройки микроструктуры металла внутри

Письма в ЖТФ, 2018, том 44, вып. 23 
УВ и последующего выброса частиц с поверхности образца. Исходя из приведенного в [5] решения методом Вентцеля-Крамерса-Бриллюэна кинетического уравнения Фоккера-Планка, описывающего распространение волны плотности распределения объектов в пространстве размеров $a$, можно записать следующую формулу для относительной плотности $P$ распределения, которая отражает существование множества локальных максимумов $P$, соответствующих наиболее вероятным (устойчивым) размерам:

$$
P \approx\left(\frac{a}{a_{0}}\right)^{-3 / 4} \cos \frac{2 \sqrt{2}}{5} \frac{\lambda}{\beta^{1 / 2}}\left(\left(\frac{a}{a_{0}}\right)^{5 / 2}-1\right) .
$$

В этой формуле во избежание чрезмерных подробностей непринципиального характера целесообразно не брать модуль косинуса, а рассматривать только положительную часть осциллирующего сомножителя. Здесь параметр $\beta \approx \hbar t_{i} / 2 m_{0} a_{0}^{2}$ ( $\hbar-$ приведенная постоянная Планка) определяется массой $m_{0}$ и размером $a_{0}$ зародыша, а также характерным параметром времени $t_{i}$ взаимодействия объектов, $\lambda \approx \sqrt{15 / 2}-$ постоянная, определяемая путем сшивки решения уравнения Фоккера-Планка для малых частиц с первым максимумом уравнения (1), соответствующим зародышу. При описании процессов внутри образца для учета интенсивности УВ параметр $t_{i}$ целесообразно принять равным периоду колебаний атомов, задаваемому ударным фронтом: $t_{i}=2 \pi \hbar / k_{\mathrm{B}} T$, где $T-$ температура во фронте УВ, $k_{\mathrm{B}}-$ постоянная Больцмана. В качестве зародыша целесообразно рассмотреть наночастицу с размером $a_{0} \equiv a_{*}=2 a_{c}$, где $a_{c}$ - размер ячейки кубической кристаллической решетки. Это отражает трансляционную симметрию решетки, т. е. образование кристаллического порядка. При описании процессов в потоке выброшенных частиц параметр $t_{i}$ целесообразно принять равным времени пробега звуковой волны по зародышу: $t_{i}=2 a_{c} / c_{0}, c_{0}-$ скорость звука в веществе образца.

Максимально возможный размер объектов можно оценить по формуле, полученной в [5] на основе соотношения неопределенностей для координаты и импульса в пространстве размеров $a$ объектов при условии сохранения массы в элементарном процессе взаимодействия объекта с зародышем:

$$
a_{\max } \approx \frac{2 m_{0} a_{0}^{3}}{9 \hbar \Delta t_{\min }}=\frac{2 \rho_{0} a_{0}^{5}}{9 \hbar \Delta t_{\min }} .
$$

Письма в ЖТФ, 2018, том 44, вып. 23 

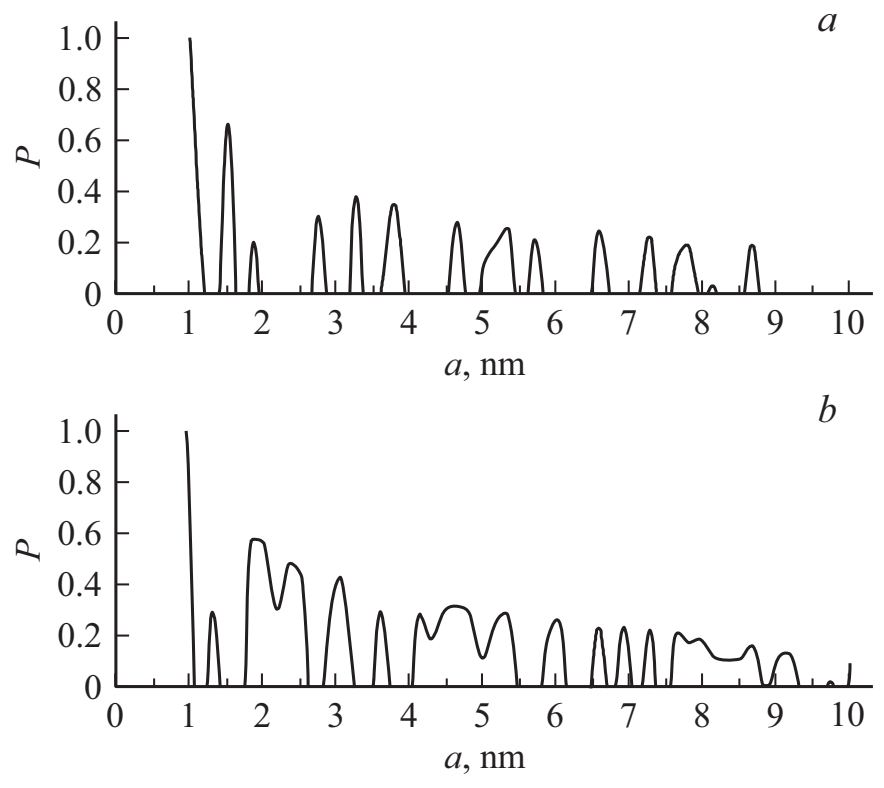

Относительная плотность распределения наночастиц свинца по размерам в УВ внутри образца при $T=300(a)$ и $500 \mathrm{~K}(b)$. Шаг расчетов равен $0.175 \mathrm{~nm}$ (атомный радиус) [6]. Наибольший по величине $P(a)$ локальный максимум после зародыша соответствует размеру $1.5(a)$ и $2 \mathrm{~nm}(b)$. Расчет „оборван“ на размере $10 \mathrm{~nm}$.

Здесь $\rho_{0}$ - плотность вещества с кубической кристаллической решеткой. В процессах внутри образца $\Delta t_{\min }=2 \pi \hbar / k T$, в процессах выброса $\Delta t_{\min }=2 a_{c} / c_{0}$.

Средние размеры объектов после выброса с поверхности образца при указанных выше режимах агрегации и при условии сохранения ближнего порядка на базе двух размеров кристаллической ячейки рассчитываются по следующим формулам $[2,5]$ :

$$
\begin{aligned}
\langle a\rangle_{s f} & =\left(\frac{75 k_{\mathrm{B}} T a_{c}^{3}}{A m_{u}}\right)^{1 / 5} t^{2 / 5}, \\
\langle a\rangle_{s m} & =\left(\frac{27 k_{\mathrm{B}} T a_{c}}{4 A m_{u}}\right)^{1 / 3} t^{2 / 3} .
\end{aligned}
$$

Письма в ЖТФ, 2018, том 44, вып. 23 
Здесь $A$ и $m_{u}$ - массовое число и атомная единица массы. Формула (3) соответствует малому потоку $(s f)$ зародышей на частицу, формула (4) — касательному взаимодействию объектов (сдвиговый механизм, $s m)$.

На рисунке приведены расчеты по формуле (1) для процессов внутри образца из свинца с параметром гранецентрированной кубической решетки $a_{c}=0.49496 \mathrm{~nm}$ [6] при температурах $T=300(a)$ и $500 \mathrm{~K}(b)$. Шаг расчетов равнялся атомному радиусу. Можно видеть, что с увеличением интенсивности УВ наибольший по величине $P(a)$ локальный максимум после зародышей смещается в сторону увеличения координаты $a$. При этом в распределении $P(a)$ появляются более широкие максимумы (сдвоенные и строенные пульсации), означающие слияние наночастиц. Аналогичные распределения $P(a)$ получены для актиноида [3]. Максимально возможный размер зерен, рассчитанный по формуле (2) для УВ в свинце при $T=300 \mathrm{~K}$, равен $a_{\max } \approx 140 \mu \mathrm{m}$, при $T=500 \mathrm{~K} \quad a_{\max } \approx 230 \mu \mathrm{m}$. В случае актиноида при $T=500 \mathrm{~K}$ $a_{\max } \approx 200 \mu \mathrm{m}$, при $T=900 \mathrm{~K} a_{\max } \approx 370 \mu \mathrm{m}$. Таким образом, рассчитанные в настоящей работе размеры твердофазных частиц, образующихся внутри макроскопических образцов из рассматриваемых металлов при ударных воздействиях, лежат в диапазоне от $\sim 1 \mathrm{~nm}$ до $\sim 370 \mu \mathrm{m}$. Он включает в себя упомянутые выше средние размеры объектов, рассчитанные в [2].

Расчеты по формуле (1) показали, что в потоках выброшенных наночастиц распределения $P(a)$ приблизительно соответствуют аналогичным распределениям в УВ внутри образца. Расчеты по формулам (3), (4) дают следующие интервалы средних размеров пылевых частиц свинца при длительностях ударного процесса $t=10^{-9}-10^{-6} \mathrm{~s}$ и указанных выше температурах: в режиме малого потока зародышей $\langle a\rangle_{s f}=0.010-0.18 \mu \mathrm{m}$; в режиме касательных взаимодействий $\langle a\rangle_{s m}=0.03-4 \mu \mathrm{m}$. Максимально возможный размер частиц свинца, оцененный по формуле (2), составляет $a_{\max } \approx 27 \mu \mathrm{m}$. Близкие значения характеристических размеров $\langle a\rangle_{s f},\langle a\rangle_{s m}$ исследуемых объектов получены при расчете для рассматриваемого актиноида. Верхняя граница $\langle a\rangle_{s m}$ и указанная величина $a_{\max }$ находятся в качественном соответствии с экспериментальными данными работ, упомянутых в [1,2]. Следует отметить, что в совокупности со спектрами $P(a)$ полученные величины $\langle a\rangle_{s f},\langle a\rangle_{s m}$ расширяют диапазон возможных размеров пылевых частиц в нанометрическую область. При этом данный кластерный подход не

Письма в ЖТФ, 2018, том 44, вып. 23 
содержит запретов на выбросы крупных мезозерен, образовавшихся в УВ внутри образца.

Средний пространственный шаг $l$ выбросов вдоль поверхности полированных образцов определяется средним расстоянием между дефектами кристаллической решетки. Если выбросы происходят вблизи вакансий с атомной концентрацией $\alpha=0.01-0.02(1-2$ at.\% вблизи температуры плавления [7]), то величину среднего шага можно оценить как $l_{v} \approx(\alpha n)^{-1 / 3} \approx 1.1-1.5 \mathrm{~nm}\left(n \approx(3.2-3.7) \cdot 10^{28} \mathrm{~m}^{-3}-\right.$ концентрации атомов $\mathrm{Pb}$ и $\delta-\mathrm{Pu})$. Это сравнимо с размером наночастиц, т.е. в случае сильной УВ выброс наночастиц на вакансиях происходит по всей ударно-нагруженной поверхности образца. В свинце при комнатной температуре вакансии находятся на расстоянии около 100 атомов [3]. Это означает, что в случае слабой УВ в свинце средний шаг выбросов наночастиц на вакансиях приблизительно равен $35 \mathrm{~nm}$ (атомный радиус $\mathrm{Pb}$ равен $0.175 \mathrm{~nm}[6]$ ). При выбросах на дислокациях величина среднего шага $l_{d}$ определяется поверхностной плотностью дислокаций, которая зависит от способа обработки (отжиг или деформация) и составляет полный диапазон $\eta_{d}=10^{10}-10^{16} \mathrm{~m}^{-2}$ [3]. Отсюда получаем $l_{d} \approx 1 / \sqrt{\eta_{d}}=0.01-10 \mu \mathrm{m}$. При выбросах на межзеренных границах максимальная величина шага $l_{\max }$ определяется величинами $a_{\max }$ в образце: $l_{\max }=a_{\max }=140-370 \mu \mathrm{m}$.

Предложенная кластерная модель дает полный расчетный диапазон характеристических размеров исследуемых нано- и мезообъектов в процессах их образования внутри ударных волн в тяжелых металлах и при последующих выбросах частиц с поверхностей макроскопических образцов. Полученные результаты могут оказаться полезными при экспериментальных исследованиях выбросов вещества с поверхности ударно-нагруженных образцов и при постопытном анализе их микроструктуры.

\section{Список литературы}

[1] Buttler W.T., Williams R.J.R., Najjar F.M. // J. Dynamic Behavior Mater. 2017. V. 3. N 2. P. 141-145.

[2] Лин Э.Э., Михайлов А.Л., Хворостин В.Н. // Письма в ЖТФ. 2016. Т. 42. B. 15 . C. $67-71$.

Письма в ЖТФ, 2018, том 44, вып. 23 
[3] Плутоний. Фундаментальные проблемы. В 2-х т. / Пер. с англ. под ред. Б.А. Надыкто, Л.Ф. Тимофеевой. Саров: Изд-во ФГУП „РФЯЦ-ВНИИЭФ“, 2003. 495 c. [Challenges in Plutonium Science. Los Alamos Science, 2000. $\mathrm{N}$ 26.].

[4] Слядников E.E. // Физ. мезомеханика. 2003. Т. 6. № 3. С. 23-28.

[5] Lin E.E. // World J. Mech. 2014. V. 4. N 6. P. 170-194.

[6] Егоров А.М. Свинец // Физический энциклопедический словарь. Т. 4 / Под ред. Б.А. Введенского, Б.М. Вула. М.: Сов. энциклопедия, 1965. С. 493.

[7] Шефбтель Н.Н. Вакансии // Физический энциклопедический словарь. Т. 1 / Под ред. Б.А. Введенского, Б.М. Вула. М.: Сов. энциклопедия, 1960. С. 219. 